\title{
Extreme curvature of shallow magma pathways controlled by competing stresses: insights from the 2018 Sierra Negra eruption
}

\author{
Timothy Davis ${ }^{1}$, Marco Bagnardi ${ }^{2,3}$, Paul Lundgren ${ }^{3}$, Eleonora Rivalta ${ }^{1,4}$ \\ ${ }^{1}$ GFZ (GeoForschungsZentrum), Physics of Earthquakes and Volcanoes, Helmholtzstraße 6/7, Building H \\ 7, 14467 Potsdam, Germany. \{davis,rivalta\}@gfz-potsdam.de \\ ${ }^{2}$ Now at Cryospheric Sciences Laboratory, NASA Goddard Space Flight Center, 8800 Greenbelt Road, \\ Greenbelt, MD, United States. marco.bagnardi@nasa.gov \\ ${ }^{3}$ Jet Propulsion Laboratory, California Institute of Technology, 4800 Oak Grove Drive, Pasadena, CA, \\ United States. paul.r.lundgren@jpl.nasa.gov \\ ${ }^{4}$ Department of Physics and Astronomy, Alma Mater Studiorum University of Bologna, V.le Berti Pichat \\ 6, Italy. eleonora.rivalta@unibo.it
}

\section{Key Points:}

- The 2018 eruption at Sierra Negra volcano, Galápagos Islands, was fed by a highly curved sill.

- The curvature of the sill's trajectory was due to competing stresses: topographic loading, magma/rock weight contrasts and additionally free surface effects.

- Shallow flat-lying intrusions are unstable and as such are extremely likely to turn at a given distance from the edifice's centre.

Corresponding author: Timothy Davis, davis@gfz-potsdam.de 


\begin{abstract}
Eruptions at shield volcanoes often occur from radially aligned linear fissures fed by bladelike magma-filled cracks (dykes). The fissures of the 2018 Sierra Negra eruption were scattered on the flank of the volcano. Space-borne radar interferometric data (InSAR) revealed that, unexpectedly, part of the eruption was fed by a $15 \mathrm{~km}$ long, tortuous and flat-lying crack (sill). Here we develop a framework that captures the full 3D kinematics of non-planar intrusions. This includes both an analytical and comprehensive numerical scheme. We constrain the models such that they match the observed ground deformation at Sierra Negra. We show that the peculiar sill trajectory is due to the competing stress gradient magnitudes being close to one another throughout its propagation. By accounting for the interaction of all these factors, these 3D models open the possibility to understand and simulate the geometry of magma transport at volcanic systems.
\end{abstract}

\title{
Plain Language Summary
}

Here, we show in unprecedented detail using space-borne radar interferometric data, a large volume eruption at Sierra Negra volcano, Galápagos Islands fed by a flat-lying crack (sill). The observations are particularly intriguing as this sill's trajectory was over 15-km-long and whilst it remained flat it was highly curved, which, cannot be explained by existing models. We employ simple fracture mechanics models to show that the sill grew away from the summit due to the stresses induced by the slope of the volcano. Further from the summit, forces caused by the magma/rock weight contrast began to compete with the slope stresses causing the sill's growth direction to turn as observed. We show how parameters such as: magma volume, weight contrast, sill depth and the tectonic stresses, play a role in defining if/where the flank eruption occurs. To summarise, we show a well constrained example of a curved sill-fed eruption, which has never been observed in such detail before. These observations warranted the use of new 3D models to help explain the process. This work shows how to analyse the paths of cracks feeding volcanic flank eruptions efficiently in 3D, and can be used to understand the potential hazard of a particular batch of magma.

\section{Introduction}

Dyking is a form of magma transport through cracks driven by the pressure of the magma. Current dyke propagation models are two-dimensional (2D), taking advantage of the observed sheet-like aspect ratios of such fractures (Dahm, 2000; Sigmundsson et al., 2015; Pinel et al., 2017). 2D models capture the processes driving many dykes, but cannot be used to explain observations of dykes twisting or segmenting, and dyke ascent followed by lateral propagation (Bagnardi et al., 2013; Xu \& Jónsson, 2014; Sigmundsson et al., 2015). One striking example of more complex propagation is the intrusion feeding the 2018 Sierra Negra eruption. Surface deformation patterns revealed by space-borne radar interferometric data (InSAR) data show a surprising geometry and trajectory of the propagating feeder. The deformation patterns point at a flat-lying magma body (sill) with a propagation direction that turned by over 90 degrees, whilst the sill remained flatlying. Magma rarely propagates for long distances as a sill. Observations from previous eruptions at the Galápagos islands show many such sills twisting into dykes before they erupt (Bagnardi et al., 2013). Rare examples of sill propagation include the May 2016 eruption at Piton de la Fournaise, La Réunion (Smittarello et al., 2019) and the intrusions tracked by the 2011-2013 El Hierro seismic swarms (Cerdeña et al., 2018; González et al., 2013). Comprehensive, three-dimensional (3D) propagation models to understand the tortuous path of such sills and dykes are not available.

Here we combine current 2D fluid-filled fracture mechanics models with the advancements from other fields in the 3D growth of fractures (Meng et al., 2013; Nejati et al., 
2016). After evaluating ground displacement observations of the 2018 Sierra Negra intrusion, we use the new models to explain the curved propagation path of the sill.

\section{Observations and data}

Sierra Negra is an intra-plate basaltic shield volcano with a maximum elevation of 1140 metres above sea level (m.a.s.l.), a shallow $(110 \mathrm{~m})$ and structurally complex $7 \mathrm{x}$ $10 \mathrm{~km}$ elliptical caldera, and is the most voluminous of the five coalescing volcanoes that form Isabela Island in the western Galápagos Archipelago, Ecuador (Reynolds et al., 1995). Thirteen effusive eruptions have occurred at Sierra Negra since 1813. The three most recent eruptions all occurred in the northern flank of the volcano and emplaced $0.90 \mathrm{~km}^{3}$ in 1979, $0.15 \mathrm{~km}^{3}$ in 2005, and $0.19 \mathrm{~km}^{3}$ of lava in 2018 (Vasconez et al., 2018). The 1979 and 2005 eruptions were fed by vents high on the northern flank and with eruptive fissures aligned parallel to the caldera rim and were likely fed by circumferential dykes (e.g., (Geist et al., 2008)). In contrast, the vents of the 2018 eruption were scattered with no preferred orientation up to $9.5 \mathrm{~km}$ from the caldera rim, at a minimum elevation of 90 m.a.s.l. There are no documented examples of vents at such low elevations in the recent history of the volcano. On the other hand, some of the higher-elevation eruptive vents of the 2018 eruption reactivated existing fissures. The 2018 eruption interrupted a thirteenyear semi-continuous period of uplift that raised the floor of the summit caldera by up to $5.2 \mathrm{~m}$ since the 2005 eruption as measured by GPS (Fig. S1), presumed to be re-pressurization of a $\sim 2 \mathrm{~km}$ deep magma reservoir.

On the 26th June 2018 at 19.40 UTC the appearance of volcanic tremor marked the beginning of the eruption. Throughout the eruption, seismicity was mainly located along the caldera fault system with fewer events in the northwestern upper flank. Caldera deflation rapidly started with the onset of eruptive activity and by the time the eruption ended on the 25th August 2018, GPS stations measured a cumulative intra-caldera subsidence of up to $\sim 8.5 \mathrm{~m}$ (Fig. S1).

Short-lived ( $<24 \mathrm{hrs}$ ) effusive eruptions from multiple fissures (Fissure $1-5$, Fig. 1) on 26-27 June were followed by a long-lasting effusive eruption from the most distal fissure (Fissure 6) between July 1st and August 25th. Geodetic monitoring by continuous GPS at Sierra Negra is limited to the summit caldera, such that the feeder-induced surface displacements were only measured by interferometric synthetic aperture radar (InSAR). The first co-eruptive synthetic aperture radar (SAR) image was acquired on 29 June at 17:50 UTC by the Japan Aerospace Exploration Agency's ALOS-2 satellite, approximately 70 hours after the onset of the seismic swarm (Fig. 1). Further SAR images were acquired on 30 June and 1 July by the European Space Agency's Sentinel-1 satellite constellation, right before the opening of Fissure 6 (Fig. 2a and b). Additional SAR images were captured during the eruption of Fissure 6 (Fig. 2c and d). Surface deformation patterns before and after Fissure 6 erupted show the trajectory for the propagating feeder (Table. S1). We estimate the location and geometry of the source of deformation using a Bayesian approach (see Fig. S2 and Table. S1 for a description of the methodology and results).

\section{Model}

Here we outline the basic principles used in our method. After this introduction, we tackle the problem both analytically and with numerical simulations.

Propagation directions of dykes have typically been predicted by maximizing the strain energy release rate (Dahm, 2000; Sigmundsson et al., 2015), on test elongations at the leading tip, thereby finding the path of least resistance. Such a method is unwieldy for true $3 \mathrm{D}$ propagation, as it would involve computing a large number of potential tip- 
Figure 1. a) Inset map showing the location of Sierra Negra volcano. Volcanoes labelled as Wolf (W), Darwin (D), Fernandina (F), Alcedo (A), Sierra Negra (S) and Cerro Azul (C). b) Interferogram spanning the sill propagation phase of the 2018 eruption. SAR data from the ALOS-2 satellite. Each colour cycle represents $11.45 \mathrm{~cm}$ displacement, positive towards the satellite (e.g. uplift) and negative away from it (e.g. subsidence). Gray polygons show the extent of the lava flows emplaced during the time period spanned by the interferogram. Yellow lines mark the location and extent of all eruptive fissures. Black triangles mark the location of GPS stations. Black arrows show the satellite orbit direction $(\sim \mathrm{N}-\mathrm{S})$, look direction $(\sim \mathrm{E}-\mathrm{W})$, and the incidence angle in degrees. Descending pass, Track 147, ScanSAR mode.

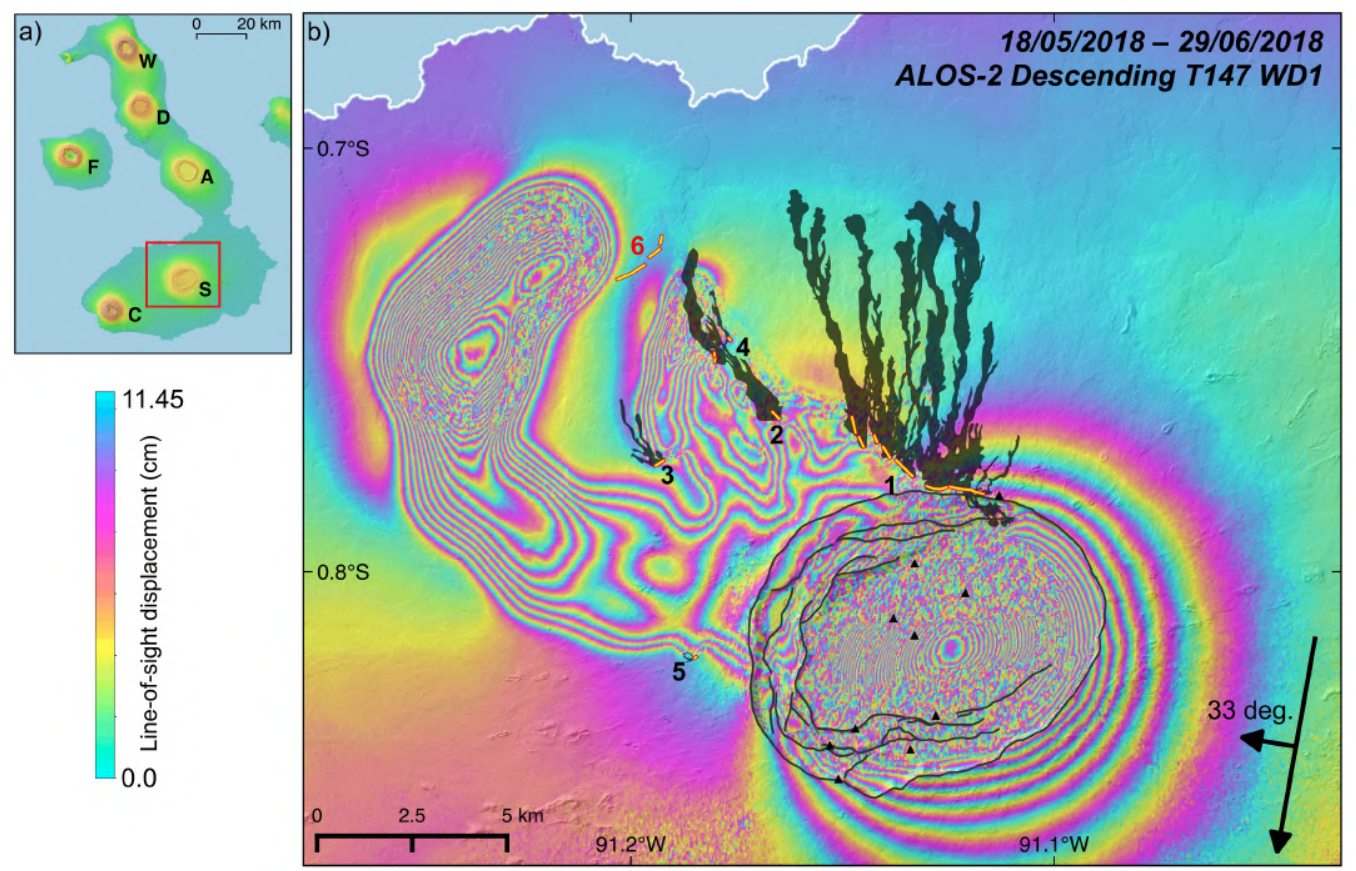


Figure 2. Interferograms of Sierra Negra spanning the sill propagation and eruption phase of the 2018 eruption. SAR data are from the Sentinel-1 satellite (a and b) and the ALOS-2 satellite (c and d). Same colourbar as Fig. 1, with each colour cycle in (a and b) as $2.8 \mathrm{~cm}$ and in (c and d) $11.45 \mathrm{~cm}$ displacement, positive towards the satellite (e.g. uplift) and negative away from it (e.g. subsidence). Black arrows show the satellite orbit direction, a) S-N b) N-S, look direction a) $\sim \mathrm{W}-\mathrm{E}$ b) $\sim \mathrm{E}-\mathrm{W}$, and the incidence angle in degrees. a) Ascending pass, Track 106, TOPS mode. b) Descending pass, Track 128, TOPS mode. c) Descending pass, Track 147, Ultra-fine Stripmap mode (SM1; pixel resolution 3.0x3.0 m). d) Ascending pass, Track 41, Fine Stripmap mode (SM3; pixel resolution $9.1 \times 5.3 \mathrm{~m}$ ). Symbols as in Fig. 1.

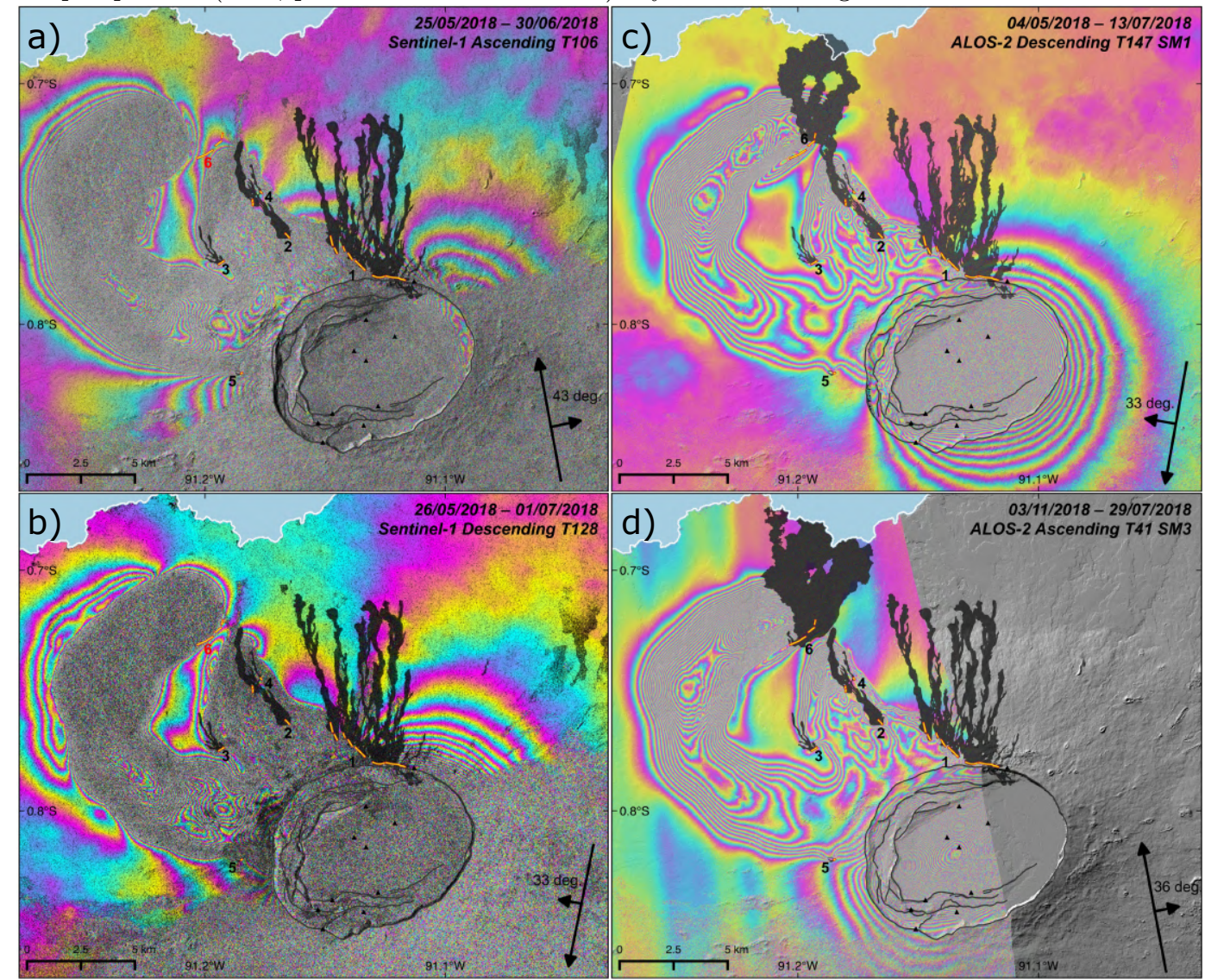


line growth patterns. Here we use a theoretically equivalent, but more flexible, approach based on the maximum stress intensity, $K$.

In our analytical approach, we reduce the sill geometry to that of a penny-shaped crack subject to stress gradients, with an opening that is compatible with the surface displacements observed along the short-axis of the sill. At selected points along the sill's path, we calculate $K$ around the tip-line (Davis et al., 2019), and assume the greatest tip-line advance occurs in the direction where $K$ is largest (akin to Paris fatigue law (Davis et al., 2020)). In our numerical simulations, we discretise the sill into triangular elements (Nikkhoo \& Walter, 2015; Davis et al., 2020) and update the tip-line at each step using the local value of $K$ as compared to the critical rock strength, $K_{c}$. The total stress intensity which is compared to the fracture toughness at a point of a crack's tip-line can be defined by a combination of the opening, sliding and tearing mode stress intensity factors (Pollard \& Fletcher, 2005) $\left(K_{I}, K_{I I}\right.$ and $\left.K_{I I I}\right)$.

$$
K=\sqrt{K_{I}^{2}+K_{I I}^{2}+\left(\frac{1}{1-\nu}\right) K_{I I I}^{2}}
$$

which relates to strain energy release rate (Tada et al., 2000) $(\mathcal{G})$ through:

$$
K=\sqrt{\frac{\mathcal{G E}}{1-\nu^{2}}} ;
$$

where $E$ is Young's modulus.

In our analytical approach, we employ stress intensity equations in a full-space. We then go on to numerically test how the free surface and the real topography would affect these results. In the numerical simulations, we compute stresses under an arbitrary topography in 3D with an external elastic stress field. As in previous 3D studies we neglect viscous effects of the contained fluid and coupling to a depressurizing chamber.

We constrain the parameters in both models using inversions of co-eruptive InSAR data along the propagation path (Fig. S2, Table. S1): depth $d=950 \mathrm{~m}$, radius $c=1900$ $\mathrm{m}$ and volume $V=1.6 \pi c^{2} \mathrm{~m}^{3}$. $V$ represents the volume of the inflated nose of the propagating fracture, which is approximately a tenth of the estimated erupted volume (Vasconez et al., 2018) $\left(0.018 \mathrm{~km}^{3}\right)$. We set the rock properties to: $\rho_{r}=2900 \mathrm{~kg} \cdot \mathrm{m}^{-3}, \mu=2 \cdot 10^{9} \mathrm{~Pa}$ and $\nu=0.35$ corresponding to the rock density, shear modulus and Poisson's ratio, respectively. These properties lie towards the more compliant end of reported stiffness values from outcropping lava flows in Kilauea, Hawaii(Bubeck et al., 2017).

\section{Effects defining the sill's path}

We begin by reducing the physics of this problem into its component parts and evaluate how these affect the sill's direction of propagation. Previous studies have found that dyke trajectories are dependent on the ratio of tectonic to topographic loading stresses (Roman \& Jaupart, 2014; Sigmundsson et al., 2015; Rivalta et al., 2019). Here we propose that contrasting magma and rock weight gradients (buoyancy) must also be considered as one of the dominant forces.

Opening stress intensity $K_{I}$ around the edge of a penny-shaped crack of volume $V$ in a full-space, subject to a constant pressure(Tada et al., 2000) is:

$$
K_{I}=\frac{3 \mu V}{4(1-\nu) c^{2} \sqrt{\pi c}}
$$

$K_{I}$ around a crack under a pressure gradient (Tada et al., 2000) is: 


$$
K_{I \alpha}=\frac{4}{3 \pi} \Delta \gamma c \sqrt{\pi c} \cos (\alpha)
$$

where $\alpha$ is the angle away from the direction of the linear stress gradient $(\Delta \gamma)$ on the crack's walls. The pressure gradient in equation 4 defines the direction of $K_{\max }$ (blue lines in Fig. 3a). As such, ignoring other effects, the direction and magnitudes of competing pressure gradients acting on the crack define its propagation direction.

We now estimate stress gradients at Sierra Negra. First, we use an analytical solution describing stresses beneath a symmetrical ridge-like topography (Savage et al., 1984)which we align at fit to the topographic profile between A-A' shown in Fig.3. This approximate topographic slope is shown in Fig.4c) and in the supplementary materials. $h$ and $v$ are the horizontal and vertical axis, respectively. We compute the horizontal gradient of vertical stress: $\delta \sigma_{v} / \delta h$, i.e., the normal stress gradient driving a flat-lying crack away from the caldera rim, at the inferred sill depth along its track. Linear stress gradients due to the difference between rock and fluid density (buoyancy) (Pollard \& Townsend, 2018) are $\left(\rho_{r}-\rho_{f}\right) g \sin (\beta)$, where $\rho_{f}$ is the magma density. The factor $\sin (\beta)$ means that if the crack is flat this gradient is zero. We set $\rho_{f}=\rho_{r}-300 \mathrm{~kg} \cdot \mathrm{m}^{-3}$ (Vigouroux et al., 2008). For the parameters above, $15 \mathrm{~km}$ from the caldera center (around where the sill began to turn eastwards) the dip needs to be around $10^{\circ}$ for the buoyancy gradient to exceed the stress gradient due to the overlying slope (Fig. S3) and drive the sill to turn away from the downslope direction (Fig. 3a).

It is well-documented that sills curve upwards, towards a free surface (Thomas \& Pollard, 1993). We find, for a penny-shaped crack, where $c / d=2$, as observed, a dip of $15^{\circ}$ results in the same $K_{I}$ increase for both buoyancy and the free surface, doubling dip's effects (see supplementary material S4).

Lastly, we test if the other intrusions to the east that fed fissures 2,3 and 4 (Fig. 1) may have attracted the sill. Two penny-shaped cracks subject to equal internal pressure separated $5 \mathrm{~km}$ from each other, as observed (tip separation of $1.2 \mathrm{~km}$ ) experience a maximal $K_{I}$ increase of $\sim 3 \%$ (Tada et al., 2000; Fabrikant, 1987). Such an increase is minor compared to the processes described earlier.

To summarise the analytical analysis, the stress gradient due to topography drives the sill away from the caldera rim. As the slope shallows, the buoyancy gradient begins to dominate even for shallowly dipping cracks, causing the sill to turn. The free surface amplifies this effect (Fig. S5). This analytical method of assessing the sill path is flexible and fast.

In order to allow interaction between all factors discussed above, we develop a 3D Boundary Element Model (Davis et al., 2019, 2020) to simulate a penny-shaped crack beneath the real edifice's topography. We include stresses due to gravitational loading and traction-free boundary conditions on the surface (Martel, 2000; Davis et al., 2019). Using orientations of the crack in the 3D space obtained by inverting surface deformation, our model explains the turning of the sill for snapshots along its path (Fig. 3), showing that it is the interaction between sill dip, slope gradients and the free surface that causes the observed turning. Note that increasing the ratio of the horizontal to vertical stress $\left(\sigma_{h} / \sigma_{v}\right)$ in the topographic loading model results in better fits.

\section{Full 3D propagation model}

Lastly, we run full 3D fracture propagation simulations (Davis et al., 2020). Here the crack is neither constrained to be planar nor circular in shape, only such that it maintains a constant $V$. The tip-line shape is recalculated at every iteration moving it forward in proportion to $K / K_{c}$, at any triangle where $K / K_{c}>1$. We remove triangular 
Figure 3. Simulating the propagation direction of fracture at selected locations a) Analytical $K_{I}$ diagram. Black circles represent the fracture, distance of the dashed gray line to the fracture edge represents $K_{I}$ magnitude, where the blue line represents $K_{\max }$ direction. Topographic contours shown in orange. b) Numerical simulation of the propagation direction at Sierra Negra. Fractures have been scaled to a $1 \mathrm{~km}$ radius for visualisation, white dashed-line represents $K_{I}$ magnitude as in a). Dip and strike directions shown, defined by inversions (Table. S1). For P7 a dip of $15^{\circ}$ is used. Dashed grey outline is a contour of sill-induced deformation from Fig. 2c). Background $\sigma_{h} / \sigma_{v}=0.5$ in topographic loading model.
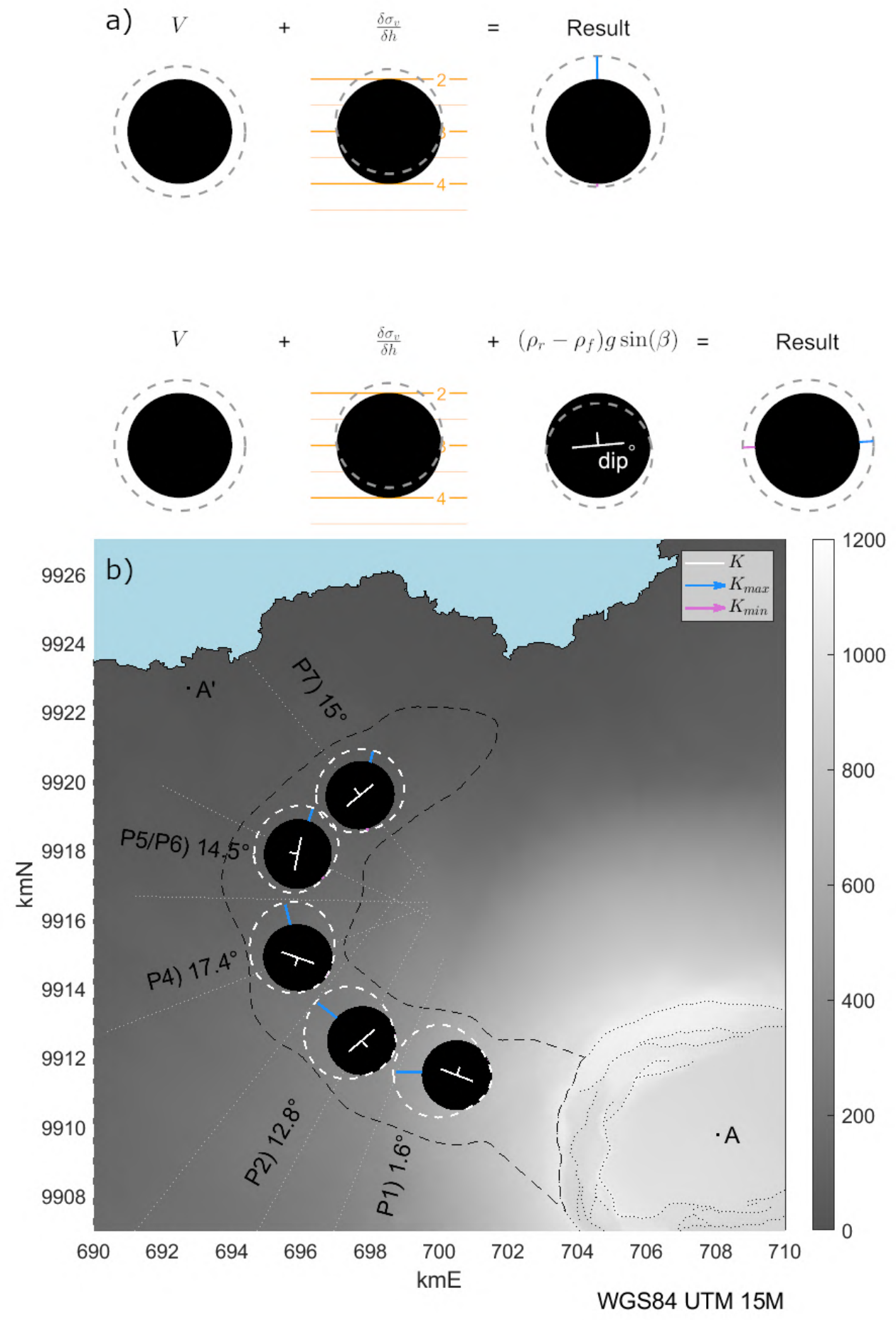
Figure 4. Numerical simulation of the sill propagation. a) Map view, b) cross-section looking along the downslope direction and c) cross-section looking along the $x$-axis with Vertical Exaggeration (V.E.). The fracture is shown at chosen locations along its computed path. Grey points are edges that closed in the previous iteration. The shaded patch in a) is the sill track and the dotted line is the caldera rim. In c) the solid line is the topographic slope used to load the body and the dashed line is the simulations free surface. Parameters used: $\beta=1^{\circ}, \rho_{f}=\rho_{r}-300$ $\mathrm{kg} / \mathrm{m}^{3}$, start depth of $1000 \mathrm{~m}, K_{c}=70 \mathrm{MPa} \cdot \mathrm{m}^{0.5}, V=1.6 \pi c^{2} \mathrm{~m}^{3}$ and $\sigma_{y y}=-4.5 \mathrm{MPa}$.

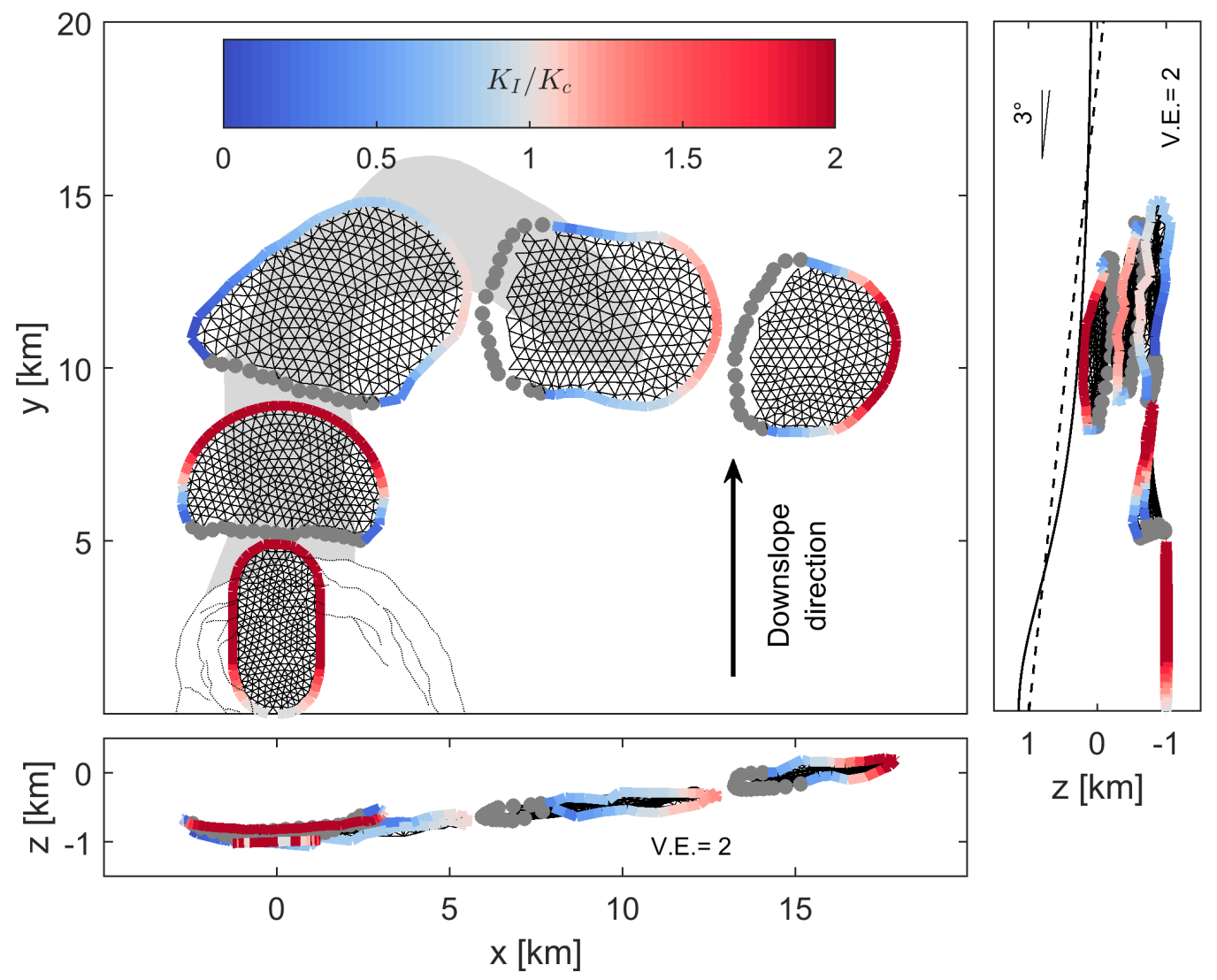

elements that shut closed. Bending or twisting of the fracture's tip-line out of its plane is calculated using the maximum circumferential stress criterion (Pollard \& Fletcher, 2005).

In this last approach, we use a planar free surface with a start height at $y=0$ of $990 \mathrm{~m}$ with a slope of $3^{\circ}$ facing to the north. The lithostatically stressed body $\left(\sigma_{h}=\right.$ $\sigma_{v}$ ) is loaded due to topography (Savage et al., 1984) (Fig. S3). We also apply throughout the body a compressive tectonic stress of 4.5 MPa directed along $\sigma_{y y}$, with $\sigma_{x x}$ the mean between $\sigma_{y y}$ and $\sigma_{z z}$, as suggested by stress indicators (Heidbach et al., 2018). Shear stresses from the topographic loading solution(Savage et al., 1984) are set to zero, on the assumption that these stresses are diminished over time by faulting, diking and longer term rock deformation processes in the edifice's flanks.

The initial crack is an ellipse $1000 \mathrm{~m}$ wide and $5000 \mathrm{~m}$ long at a depth of $1000 \mathrm{~m}$ below sea level, dipping to the west by $\beta=1^{\circ} . K_{c}$ is set to $70 \mathrm{MPa} \cdot \mathrm{m}^{0.5}$. We find when the fracture gets to a certain distance away from the caldera centre, it begins to turn and 
propagates east (Fig. 4). By changing the values of the parameters one at a time, we investigate the sensitivity of the path to the input parameters and initial geometry (Fig. 5). Reducing the initial start $\operatorname{dip} \beta$ or the buoyancy reduces the force driving the sill eastwards, causing the sill to stall as the topography shallows (Fig. 5a/b). The start depth defines when the free surface attraction takes effect (Fig. S5f), such that only shallower sills can propagate eastwards (Fig. 5c). Flipping the start dip direction such that it is west facing results in a mirror image of the path shown. The fracture toughness and volume define how far the sill can travel downslope as the topography shallows. These also control the sill width, reducing the buoyancy force when this is smaller, again trapping the sill (Fig. 5d/e). Increasing the material stiffness will have a similar effect to increasing the fluid volume, see Eq. 3. When the tectonic compressive stress is reduced, in places $\sigma_{v}$ becomes the most compressive stress, causing the sills track to become very unstable with the sill quickly rising to the surface (Fig. 5f). 
Figure 5. Effects of differing parameters on the simulated sill path, each sub-figure shows two simulations, from above and in cross section. In each sub-figure, one trajectory shown gets trapped and the other erupts. Fracture paths from the simulations are shown as coloured patches, where the blue is trapped and the pink erupts. The final mesh from each simulation, with the tip-line value of $K$ is also shown, as in Fig. 4. In each simulation we changed one parameter with respect to Fig. 4 , as follows: a) erupted: $\beta=1.5^{\circ}$, trapped: $\beta=0.5^{\circ}$. b) erupted: $\rho_{f}=\rho_{r}-450 \mathrm{~kg} / \mathrm{m}^{3}$, trapped: $\rho_{f}=\rho_{r}-150 \mathrm{~kg} / \mathrm{m}^{3}$. c) Start depth, erupted: $800 \mathrm{~m}$, trapped: $1200 \mathrm{~m} . \mathrm{d})$ erupted: $K_{c}=55 \mathrm{MPa} \cdot \mathrm{m}^{0.5}$, trapped: $K_{c}=85 \mathrm{MPa} \cdot \mathrm{m}^{0.5}$. e) erupted: $V=1.8 \pi c^{2}$ $\mathrm{m}^{3}$, trapped $V=1.4 \pi c^{2} \mathrm{~m}^{3}$. f) erupted: $\sigma_{y y}=-3 \mathrm{MPa}$, trapped $\sigma_{y y}=-6 \mathrm{MPa}$. These parameters are also shown as text next to the final mesh of each simulation.
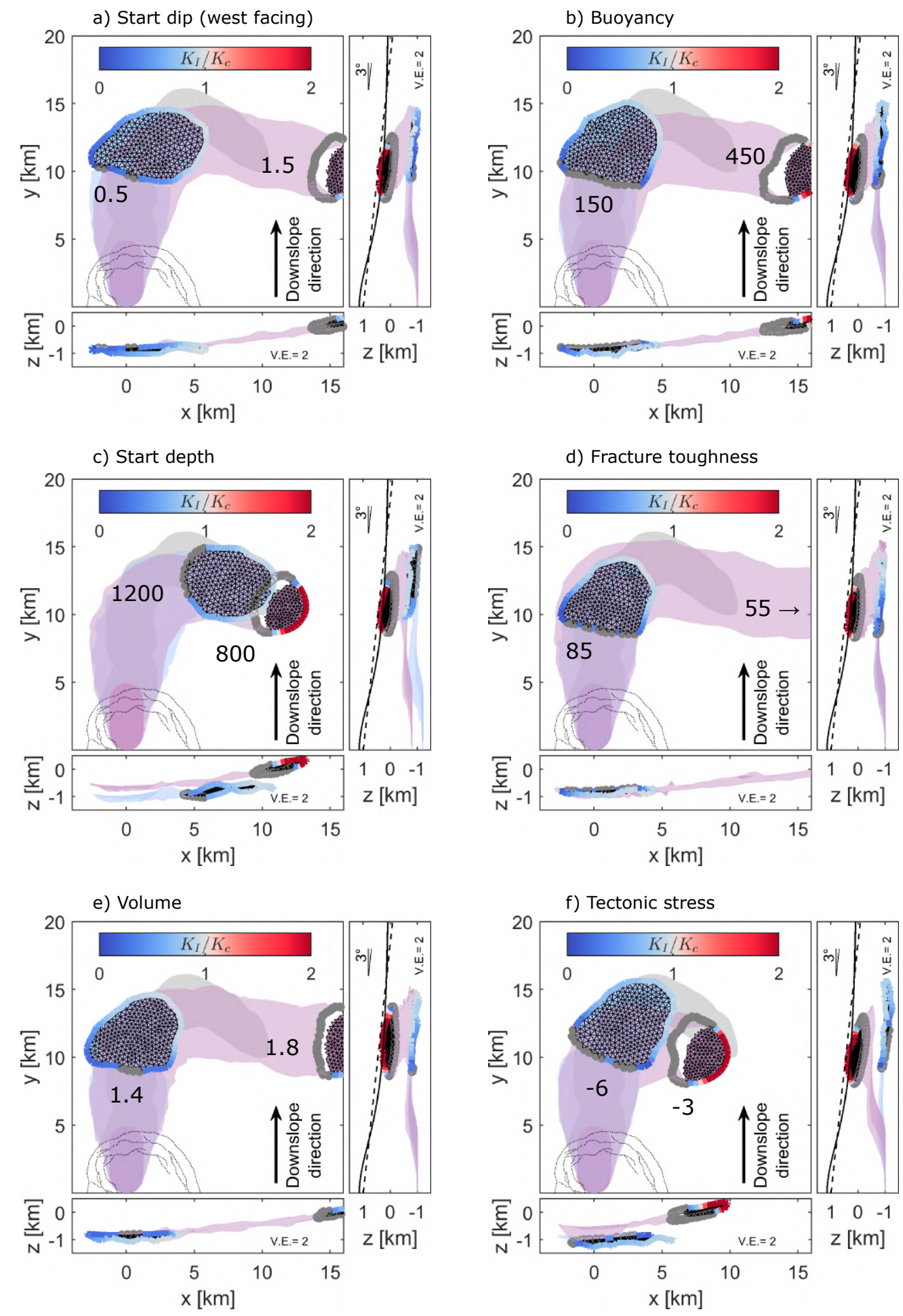
The simulations compare well with the observed trajectory; the sill was destined to turn, although it could have stalled or erupted earlier on its path.

\section{Discussion and conclusions}

Firstly, we have developed a simple analytical model where we place a test-crack at a point along the propagation path and evaluate how different stress gradients, rock and magma parameters contribute to the propagation direction. This can be applied to assess the dominant factors controlling an intrusion's path. For a given set of parameters, using the equations above, one can also efficiently assess in which direction, and how far, an intrusion can propagate. This may help in mitigating the risk linked to flank eruptions.

Secondly, we have outlined a numerical scheme where a dyke is discretised using triangular, mixed-mode dislocations, allowing for simulation of non-planar and non-uniform tip-line advance. For a given set of start parameters, this can simulate the entire propagation geometry due to a given stress state and start volume. This can capture the full 3D growth and migration. This scheme is less time-efficient (in the order of hours for one simulation) but is flexible and accounts for interacting processes.

It is of note that for this intrusion there are strong parameter trade-offs. By simulating the geometries of multiple observed flank eruption feeders, this scheme can be used to retrieve better constraints on the state of edifice stresses, in particular the tectonic directions and the ratio of horizontal to vertical stress (Rivalta et al., 2019).

Recent developments in hydrofracturing studies have shown how 3D fracture propagation models that include fluid flow within the fracture are possible to implement, for planar fractures (Salimzadeh et al., 2020; Zia \& Lecampion, 2020). Such schemes could be coupled to the model presented here to explain both the spatial and temporal evolution of sills and dykes (Pinel et al., 2017; Zia \& Lecampion, 2020; Salimzadeh et al., 2020 ). It is of note that the simulation time increases rapidly when including this process.

Previous flank volcanism at Galápagos volcanoes has been fed by radial and circumferential dykes (Chadwick Jr \& Dieterich, 1995; Bagnardi et al., 2013). Here we have shown evidence of flank volcanism fed by a long curving sill. We find that trajectories of shallow sills underneath topography will be unstable and defined by a delicate balance between buoyancy forces, topographic load, external stresses and the free surface. Still, trajectories may be anticipated, provided all those factors are well-constrained and their interaction is accounted for, within three-dimensional dyke propagation models. By combining such models with careful analysis of high-resolution crustal deformation data, we showed that such parameters as well as the state of stress of the volcano can be well constrained, reducing the uncertainties in the hazard.

\section{Acknowledgments}

T Davis is funded by the DFG-ICDP grant N. RI 2782/3-1. M. Bagnardi was supported by an appointment to the NASA Postdoctoral Program at the Jet Propulsion Laboratory, administered by the Universities Space Research Association (USRA) through a contract with NASA. Part of this research was carried out at the Jet Propulsion Laboratory, California Institute of Technology, under a contract with the National Aeronautics and Space Administration (grant 281945.02.47.04.51).

Data availability statement: InSAR data used in this manuscript are available at https://doi.org/10.5281/zenodo.4728054. Sentinel-1 raw SAR data that support the findings of this study are publicly available at https://scihub.copernicus.eu.ALOS 
-2 raw SAR data availability is restricted to PI investigation at www.eorc.jaxa.jp/ALOS/ en/.

Code availability statement: The code used for 3D boundary element numerical analysis in this study was the open source Julia (Julia-1.5.0) code https://doi.org/ 10.5281/zenodo.4726796 and https://doi.org/10.5281/zenodo.4727208 with an interface (https://doi.org/10.5281/zenodo.4727190) with the Computational Geometry Algorithms Library (CGAL-4.13.1) software $(\mathrm{C}++)$ for meshing. The scripts used in this analysis are uploaded in the repository: https://doi.org/10.5281/zenodo.4727080, noting some of the MATLAB codes in this rely on functions from the author's open source repository: https://doi.org/10.5281/zenodo.3694164.

Author Contributions: T.D and M.B coordinated the work and wrote the initial manuscript. M.B and P.L acquired and analysed the InSAR and GPS data in this study. This analysis provided the evolution and geometry of the sill. T.D and E.R conceptualised the analytical and numerical fracture mechanics that form the interpretation in this work. T.D wrote the analytical and numerical fracture mechanics codes used in this study. All authors have read and revised the manuscript and contributed ideas to the research.

\section{References}

Bagnardi, M., Amelung, F., \& Poland, M. P. (2013). A new model for the growth of basaltic shields based on deformation of fernandina volcano, galápagos islands. Earth and Planetary Science Letters, 377, 358-366.

Bagnardi, M., \& Hooper, A. (2018). Inversion of surface deformation data for rapid estimates of source parameters and uncertainties: A bayesian approach. Geochemistry, Geophysics, Geosystems, 19(7), 2194-2211.

Bubeck, A., Walker, R., Healy, D., Dobbs, M., \& Holwell, D. (2017). Pore geometry as a control on rock strength. Earth and Planetary Science Letters, 457, $38-48$.

Cerdeña, I. D., García-Cañada, L., Benito-Saz, M., del Fresno, C., Lamolda, H., de Pablo, J. P., \& Sanz, C. S. (2018). On the relation between ground surface deformation and seismicity during the 2012-2014 successive magmatic intrusions at el hierro island. Tectonophysics, 744, 422-437. doi: 10.1016/j.tecto.2018.07.019

Chadwick Jr, W., \& Dieterich, J. (1995). Mechanical modeling of circumferential and radial dike intrusion on galapagos volcanoes. Journal of Volcanology and Geothermal Research, 66(1-4), 37-52.

Chen, C. W., \& Zebker, H. A. (2001). Two-dimensional phase unwrapping with use of statistical models for cost functions in nonlinear optimization. JOSA A, $18(2), 338-351$.

Dahm, T. (2000). Numerical simulations of the propagation path and the arrest of fluid-filled fractures in the earth. Geophysical Journal International, 141(3), 623-638.

Davis, T., Healy, D., \& Rivalta, E. (2019). Slip on wavy frictional faults: Is the 3rd dimension a sticking point? Journal of Structural Geology, 119, 33-49. doi: 10 .1016/j.jsg.2018.11.009

Davis, T., Rivalta, E., \& Dahm, T. (2020). Critical fluid injection volumes for uncontrolled fracture ascent. Geophysical Research Letters, e2020GL087774.

Decriem, J., Árnadóttir, T., Hooper, A., Geirsson, H., Sigmundsson, F., Keiding, M., ... others (2010). The 2008 may 29 earthquake doublet in sw iceland. Geophysical Journal International, 181(2), 1128-1146.

Fabrikant, V. (1987). Close interaction of coplanar circular cracks in an elastic medium. Acta Mechanica, 67 (1-4), 39-59.

Geist, D. J., Harpp, K. S., Naumann, T. R., Poland, M., Chadwick, W. W., 
Hall, M., \& Rader, E. cano, galápagos, ecuador. 10.1007/s00445-007-0160-3
(2008). The 2005 eruption of sierra negra volBulletin of Volcanology, 70(6), 655-673. doi:

González, P. J., Samsonov, S. V., Pepe, S., Tiampo, K. F., Tizzani, P., Casu, F., ... Sansosti, E. (2013). Magma storage and migration associated with the 20112012 el hierro eruption: Implications for crustal magmatic systems at oceanic island volcanoes. Journal of Geophysical Research: Solid Earth, 118(8), 43614377. doi: 10.1002/jgrb.50289

Heidbach, O., Rajabi, M., Cui, X., Fuchs, K., Müller, B., Reinecker, J., ... others (2018). The world stress map database release 2016: Crustal stress pattern across scales. Tectonophysics, 744, 484-498.

Martel, S. J. (2000). Modeling elastic stresses in long ridges with the displacement discontinuity method. Pure and Applied Geophysics, 157(6-8), 1039-1057.

Meng, C., Maerten, F., \& Pollard, D. D. (2013). Modeling mixed-mode fracture propagation in isotropic elastic three dimensional solid. International Journal of Fracture, 179(1-2), 45-57. doi: 10.1007/s10704-012-9771-6

Nejati, M., Paluszny, A., \& Zimmerman, R. W. (2016). A finite element framework for modeling internal frictional contact in three-dimensional fractured media using unstructured tetrahedral meshes. Computer Methods in Applied Mechanics and Engineering, 306, 123-150. doi: 10.1016/j.cma.2016.03.028

Nikkhoo, M., \& Walter, T. R. (2015). Triangular dislocation: an analytical, artefactfree solution. Geophysical Journal International, 201(2), 1119-1141.

Okada, Y. (1985). Surface deformation due to shear and tensile faults in a halfspace. Bulletin of the seismological society of America, 75(4), 1135-1154.

Pinel, V., Carrara, A., Maccaferri, F., Rivalta, E., \& Corbi, F. (2017). A two-step model for dynamical dike propagation in two dimensions: Application to the july 2001 etna eruption. Journal of Geophysical Research: Solid Earth, 122(2), 1107-1125. doi: 10.1002/2016JB013630

Pollard, D. D., \& Fletcher, R. C. (2005). Fundamentals of structural geology. Cambridge University Press.

Pollard, D. D., \& Townsend, M. R. (2018). Fluid-filled fractures in earth's lithosphere: Gravitational loading, interpenetration, and stable height of dikes and veins. Journal of Structural Geology, 109, 38-54. doi: 10.1016/j.jsg.2017.11.007

Reynolds, R. W., Geist, D., \& Kurz, M. D. (1995). Physical volcanology and structural development of sierra negra volcano, isabela island, galápagos archipelago. Geological Society of America Bulletin, 107(12), 1398-1410.

Rivalta, E., Corbi, F., Passarelli, L., Acocella, V., Davis, T., \& Di Vito, M. A. (2019). Stress inversions to forecast magma pathways and eruptive vent location. Science advances, 5(7), eaau9784.

Roman, A., \& Jaupart, C. (2014). The impact of a volcanic edifice on intrusive and eruptive activity. Earth and Planetary Science Letters, 408, 1-8.

Rosen, P., Gurrola, E., Agram, P. S., Sacco, G. F., \& Lavalle, M. (2015). The insar scientific computing environment (isce): A python framework for earth science. AGUFM, 2015, IN11C-1789.

Salimzadeh, S., Zimmerman, R. W., \& Khalili, N. (2020). Gravity hydraulic fracturing: A method to create self-driven fractures. Geophysical Research Letters, e2020GL087563. doi: 10.1029/2020GL087563

Savage, W. Z., Powers, P. S., \& Swolfs, H. S. (1984). In situ geomechanics of crystalline and sedimentary rocks; part $v$, rvt, a fortran program for an exact elastic solution for tectonics and gravity stresses in isolated symmetric ridges and valleys (Tech. Rep.). Denver, Colorado: US Geological Survey,.

Sigmundsson, F., Hooper, A., Hreinsdóttir, S., Vogfjörd, K. S., Ófeigsson, B. G., Heimisson, E. R., ... others (2015). Segmented lateral dyke growth in a rifting event at bárðarbunga volcanic system, iceland. Nature, 517(7533), 191-195. 
Smittarello, D., Cayol, V., Pinel, V., Peltier, A., Froger, J.-L., \& Ferrazzini, V. (2019). Magma propagation at piton de la fournaise from joint inversion of insar and gnss. Journal of Geophysical Research: Solid Earth, 124(2), 13611387.

Sun, R. J. (1969). Theoretical size of hydraulically induced horizontal fractures and corresponding surface uplift in an idealized medium. Journal of Geophysical Research, 74 (25), 5995-6011.

Tada, H., Paris, P., \& Irwin, G. (2000). The stress analysis of cracks handbook; third edition. New York: ASME Press.

Thomas, A. L., \& Pollard, D. D. (1993). The geometry of echelon fractures in rock: implications from laboratory and numerical experiments. Journal of Structural Geology, 15(3-5), 323-334.

Vasconez, F. J., Ramón, P., Hernandez, S., Hidalgo, S., Bernard, B., Ruiz, M., ... Ruiz, G. (2018). The different characteristics of the recent eruptions of fernandina and sierra negra volcanoes (galápagos, ecuador). Volcanica, 1(2), $127-133$.

Vigouroux, N., Williams-Jones, G., Chadwick, W., Geist, D., Ruiz, A., \& Johnson, D. (2008). 4d gravity changes associated with the 2005 eruption of sierra negra volcano, galápagos. Geophysics, 73(6), WA29-WA35.

Wessel, B., Huber, M., Wohlfart, C., Marschalk, U., Kosmann, D., \& Roth, A. (2018). Accuracy assessment of the global tandem-x digital elevation model with gps data. ISPRS Journal of Photogrammetry and Remote Sensing, 139, $171-182$

Xu, W., \& Jónsson, S. (2014). The 2007-8 volcanic eruption on jebel at tair island (red sea) observed by satellite radar and optical images. Bulletin of Volcanology, 76 (2), 795. doi: 10.1007/s00445-014-0795-9

Zia, H., \& Lecampion, B. (2020). Pyfrac: A planar 3d hydraulic fracture simulator. Computer Physics Communications, 255(107368), 1-11. doi: 10.1016/j.cpc .2020.107368 